\title{
Which people should take aspirin for primary prevention of cardiovascular disease?
}

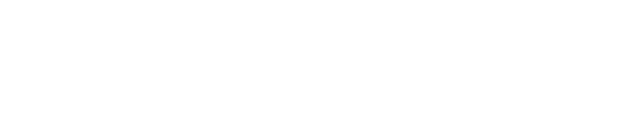

\section{Roberto Lozano' \\ Maria-Esther Franco ${ }^{2}$ \\ 'Pharmacy Department, ${ }^{2}$ Haematology Department, Hospital Real de Nuestra Señora de Gracia, Zaragoza, Spain}

\section{Dear editor}

A single trial, ISIS-2, ${ }^{1}$ in 1988 , demonstrated the utility of daily aspirin in the setting of acute myocardial infarction, reducing the risk of vascular death by $23 \%$. In addition, aspirin has also proven effective in the setting of acute ischemic stroke. ${ }^{2}$ Thus, for a subset of the general population, aspirin may help to prevent heart attacks and strokes. In fact, at low doses, in the range of 75 to $100 \mathrm{mg}$ per day, aspirin prevents the progression of existing cardiovascular disease (CVD), including coronary heart disease, stroke and peripheral arterial disease, and reduces the frequency of cardiovascular events in patients with history of $\mathrm{CVD},{ }^{3,4}$ referred to as secondary prevention. Although the benefits of aspirin for secondary prevention of CVD are well known, its use in primary prevention of CVD, defined as prevention of the first occurrence of CVD for all patients without clinical CVD, including those with diabetes mellitus and those without clinical evidence of atherosclerotic disease who are at higher CVD risk, is less clear and controversial results have been obtained. In fact, the results of several studies using aspirin for primary prevention of CVD have generally shown more modest reductions of major vascular events compared with secondary prevention ( $12 \%$ vs $23 \%)$. ${ }^{3,5}$

In this regard, the health study of women, ${ }^{6}$ the hypertension optimal treatment (HOT) study, ${ }^{7,8}$ the primary prevention project,,${ }^{9,10}$ the health study research group, ${ }^{11}$ the British doctors' trial, ${ }^{12}$ and the thrombosis prevention trial, ${ }^{13}$ indicate that aspirin therapy is associated with a significant reduction of $19 \%$ in the risk of stroke and no reduction in the risk of myocardial infarction in women; and a significant reduction of $32 \%$ in the risk of myocardial infarction and a non-significant increase in the risk of stroke in men. However, in all cases, aspirin significantly increased the risk of bleeding, as the main important side effect. ${ }^{14}$

In this context, because fatal and non-fatal thrombotic events (eg, stroke and/or myocardial infarction events) are usually prevented by aspirin, in an order of magnitude lower than in secondary prevention, and overall risk for bleeding events (eg, intracranial and/or subarachnoid hemorrhage events) are generally increased by aspirin, in an order of magnitude equal to secondary prevention, aspirin appears to offer little benefit for the primary prevention of CVD.

Moreover, in the vast majority of primary prevention studies, the overall risk level for CVD events was very $l \mathrm{w}^{5}$ and the events rate was much lower than expected, leading to studies with less power to detect differences in the primary prevention of CVD. In addition to this, it must add a greater use in general population of preventive medications for different atherosclerotic risk factors, such as antihypertensive and lipid-lowering drugs, and other preventive measures, which together result in fewer events than expected. ${ }^{15}$
Correspondence: Roberto Lozano Pharmacy Department, Hospital Real de Nuestra Señora de Gracia, C/Ramón y Cajal 60, 50004 Zaragoza, Spain

Tel +34976764522

Fax +34976764555

Email rlozano@salud.aragon.es
cC) (i) (5) 2015 Lozano and Franco. This work is published by Dove Medical Press Limited, and licensed under Creative Commons Attribution - Non Commercial (unported, v3.0) BY LC License. The full terms of the License are available at http://creativecommons.org/licenses/by-nc/3.0/. Non-commercial uses of the work are permitted without any further permission from Dove Medical Press Limited, provided the work is properly attributed. Permissions beyond the scope of the License are administered by Dove Medical Press Limited. Information on
how to request permission may be found at: http://www.dovepress.com/permissions.php 
Accordingly, it was more difficult to achieve an overall risk reduction of cardiovascular events than in secondary prevention, ${ }^{2,3,5}$ and most studies concluded that low-dose aspirin does not significantly reduce the risk of cardiovascular death, non-fatal stroke (ischemic or hemorrhagic) or non-fatal myocardial infarction in subjects without prior CVD. ${ }^{16}$

Thus, using aspirin, in a cost-effective manner and with a good risk-benefit balance, for primary prevention of CVD, we must consider that patients are affected by different atherosclerotic risk factors (eg, hypertension, dyslipidemia, and diabetes mellitus) and, therefore, the preventive effects of aspirin on CVD will be heterogeneous. So, it will be necessary to study these preventive effects, for each type of individual cardiovascular event (eg, ischemic or hemorrhagic stroke, fatal or non-fatal myocardial infarction) among the different subgroups of patients, stratified according to cardiovascular risk factors studied, eg, hypertension, dyslipidemia, diabetes mellitus, sex, age, smoking, family history of premature CVD, blood pressure $(<120 / 75 \mathrm{mmHg}, 120-129 / 75-84 \mathrm{mmHg}$, $130-139 / 85-89 \mathrm{mmHg}$, and $\geq 140 / \geq 90 \mathrm{mmHg}$ ), body mass index $(<25.0,25.0-29.9$, and $\geq 30.0)$ and/or 10-year cardiovascular risk of $6 \%-10 \% .{ }^{16}$ This would be the case for the following ongoing clinical trials: the ASCEND study, involving aspirin for patients 40 years and older with type 1 or type 2 diabetes; ${ }^{17}$ the ARRIVE study, testing aspirin in middle aged and older patients who are at moderate risk based on the presence of multiple risk factors for CVD; ${ }^{18}$ and the ASPREE study, testing aspirin in individuals older than 70 years. ${ }^{19}$

With these data, it will be possible to demonstrate the presence or absence of a preventive effect of low-dose aspirin and, consequently, the benefit of aspirin treatment for primary prevention in certain types of patients. However, so long as clinical trials are conducted and until completion, the use of aspirin for primary prevention of CVD should target patients at high cardiovascular risk: physicians should evaluate the risks and benefits of aspirin therapy for primary prevention and incorporate patient preferences.

\section{Disclosure}

The authors have no conflicts of interest to disclose in this work.

\section{References}

1. No authors listed. Randomized trial of intravenous streptokinase, oral aspirin, both, or neither among 17187 cases of suspected acute myocardial infarction: ISIS-2. ISIS-2 (Second International Study of Infarct Survival) Collaborative Group. Lancet. 1988;2(8607):349-360.
2. Antithrombotic Trialists' Collaboration. Collaborative meta-analysis of randomized trials of antiplatelet therapy for prevention of death, myocardial infarction, and stroke in high-risk patients. BMJ. 2002; 324(7329):71-86.

3. Antithrombotic Trialists' (ATT) Collaboration; Baigent C, Blackwell L, et al. Aspirin in the primary and secondary prevention of vascular disease: collaborative meta-analysis of individual participant data from randomised trials. Lancet. 2009;373(9678):1849-1860.

4. Hall SL, Lorenc T. Secondary prevention of coronary artery disease. Am Fam Physician. 2010;81(3):289-296.

5. Bartolucci AA, Tendera M, Howard G. Meta-analysis of multiple primary prevention trials of cardiovascular events using aspirin. Am J Cardiol. 2011;107(12):1796-1801.

6. Ridker PM, Cook NR, Lee IM, et al. A Randomized Trial of Low-Dose Aspirin in the Primary Prevention of Cardiovascular Disease in Women. N Engl J Med. 2005;352(13):1293-1304.

7. Hansson L, Zanchetti A, Carruthers SG, et al. Effects of intensive blood-pressure lowering and low-dose aspirin in patients with hypertension: principal results of the Hypertension Optimal Treatment (HOT) randomised trial. Lancet. 1998;351(9118):1755-1762.

8. Kjeldsen SE, Kolloch RE, Leonetti G, et al. Influence of gender and age on preventing cardiovascular disease by antihypertensive treatment and acetylsalicylic acid: the HOT study. J Hypertens. 2000;18(5): 629-642.

9. de Gaetano G; Collaborative Group of the Primary Prevention Project. Low-dose aspirin and vitamin $\mathrm{E}$ in people at cardiovascular risk: a randomised trial in general practice. Lancet. 2001;357(9250):89-95.

10. Sacco M, Pellegrini F, Roncaglioni MC, et al. Primary prevention of cardiovascular events with low-dose aspirin and vitamin $\mathrm{E}$ in type 2 diabetic patients: results of the Primary Prevention Project (PPP) trial. Diabetes Care. 2003;26(12):3264-3272.

11. No authors listed. Final report on the aspirin component of the ongoing Physicians' Health Study. Steering Committee of the Physicians' Health Study Research Group. N Engl J Med. 1989;321(3):129-135.

12. Peto R, Gray R, Collins R, et al. Randomised trial of prophylactic daily aspirin in British male doctors. Br Med J (Clin Res Ed). 1988; 296(6618):313-316.

13. No authors listed. Thrombosis prevention trial: randomised trial of lowintensity oral anticoagulation with warfarin and low-dose aspirin in the primary prevention of ischaemic heart disease in men at increased risk. The Medical Research Council's General Practice Research Framework. Lancet. 1998;351(9098):233-241.

14. Huang ES, Strate LL, Ho WW, Lee SS, Chan AT. Long Term Use of Aspirin and the Risk of Gastrointestinal Bleeding. Am J Med. 2011; 124(5):426-433.

15. Gaziano JM, Greenland P. When Should Aspirin Be Used for Prevention of Cardiovascular Events? JAMA. 2014;312(23):2503-2504.

16. Ikeda Y, Shimada K, Teramoto T, et al. Low-Dose Aspirin for Primary Prevention of Cardiovascular Events in Japanese Patients 60 Years or Older With Atherosclerotic Risk Factors A Randomized Clinical Trial. JAMA. 2014;312(23):2510-2520.

17. University of Oxford. ASCEND: A Study of Cardiovascular Events iN Diabetes. Available from: https://clinicaltrials.gov/ct2/show/ NCT00135226. NLM identifier: NCT00135226. Accessed June 9, 2015.

18. Bayer. A Study to Assess the Efficacy and Safety of Enteric-Coated Acetylsalicylic Acid in Patients at Moderate Risk of Cardiovascular Disease (ARRIVE). Available from: https://clinicaltrials.gov/ct2/show/ NCT00501059. NLM identifier: NCT00501059. Accessed June 9, 2015.

19. Minneapolis Medical Research Foundation. Aspirin in Reducing Events in the Elderly (ASPREE). Available from: https://clinicaltrials.gov/ct2/ show/NCT01038583. NLM identifier: NCT01038583. Accessed June 9, 2015. 
Dove Medical Press encourages responsible, free and frank academic debate. The content of the Therapeutics and Clinical Risk Management 'letters to the editor' section does not necessarily represent the views of Dove Medical Press, its officers, agents, employees, related entities or the Therapeutics and Clinical Risk Management editors. While all reasonable steps have been taken to confirm the content of each letter, Dove Medical Press accepts no liability in respect of the content of any letter, nor is it responsible for the content and accuracy of any letter to the editor.

Therapeutics and Clinical Risk Management

Dovepress

\section{Publish your work in this journal}

Therapeutics and Clinical Risk Management is an international, peerreviewed journal of clinical therapeutics and risk management, focusing on concise rapid reporting of clinical studies in all therapeutic areas, outcomes, safety, and programs for the effective, safe, and sustained use of medicines. This journal is indexed on PubMed Central, CAS,
EMBase, Scopus and the Elsevier Bibliographic databases. The manuscript management system is completely online and includes a very quick and fair peer-review system, which is all easy to use. Visit http://www.dovepress.com/testimonials.php to read real quotes from published authors.

Submit your manuscript here: http://www.dovepress.com/therapeutics-and-clinical-risk-management-journal 